Original Research Paper

\title{
The Dynamic of Afamin and Alpha-Fetoprotein Expression during Rat Liver Development
}

\author{
1,2,3 Indriyani, 1,2,4*Isabella Kurnia Liem, ${ }^{2,5}$ Puspita Eka Wuyung, \\ ${ }^{1,2,6}$ Msy Rulan Adnindya, ${ }^{1,2,7}$ Ahmad Azmi Nasution, ${ }^{1,2,6}$ Wardiansah and ${ }^{8}$ Ahmad Aulia Jusuf \\ ${ }^{I}$ Department of Anatomy, Faculty of Medicine, Universitas Indonesia, Jakarta, Indonesia \\ ${ }^{2}$ Master Program in Biomedical Sciences, Faculty of Medicine, Universitas Indonesia, Jakarta, Indonesia \\ ${ }^{3}$ Department of Anatomy, Faculty of Medicine, Universitas Muhammadiyah Palembang, Palembang, Indonesia \\ ${ }^{4}$ Integrated Laboratory, Faculty of Medicine, Universitas Indonesia \\ ${ }^{5}$ Departement of Anatomical Pathology, Faculty of Medicine, Universitas Indonesia, Jakarta, Indonesia \\ ${ }^{6}$ Department of Anatomy, Faculty of Medicine, Sriwijaya University, Palembang, Indonesia \\ ${ }^{7}$ Department of Anatomy, Faculty of Medicine and Health Science, Universitas Bengkulu, Bengkulu, Indonesia \\ ${ }^{8}$ Departement of Histology, Faculty of Medicine, Universitas Indonesia, Jakarta, Indonesia
}

Article history

Received: 14-10-2020

Revised: 29-01-2021

Accepted: 29-01-2021

Corresponding Author:

Isabella Kurnia Liem

Department of Anatomy,

Faculty of Medicine,

Universitas Indonesia, Jakarta,

Indonesia

Email: bellajo04@gmail.com

\begin{abstract}
Liver has a high level of Alpha-fetoprotein which is assumed to be important for mammalian development. However, Alpha-fetoprotein knockout studies in mice suggested that despite the absence of Alphafetoprotein, mice developed normally; the only abnormality observed was infertility in female mice. There are indications that Afamin, a protein that has a gene sequence located on the same chromosome as Alpha-fetoprotein, may compensate for the absence of Alpha-fetoprotein during embryonic development. Nevertheless, research on the dynamics of Afamin expression and its correlation with Alpha-fetoprotein has not been reported. Therefore, it has been done a baseline study to determine the pattern and distribution of Alpha-fetoprotein expression and its correlation with Afamin expression in the developing rat liver. An analytic observational study was performed to study the expression of Afamin and Alpha-fetoprotein in the rat embryos (embryonic day/ED12.5, ED14.5, ED16.5, ED18.5), neonates and adults using an immunohistochemistry technique by assessing the location and intensity of expression using the Immunohistochemistry Optical density score. Afamin started to express in ED18.5 and was evenly distributed in the hepatocytes and was maintained until adulthood. Whereas, Alpha-fetoprotein has been seen at ED12.5 and was distributed evenly in the hepatoblast. At ED18.5, Alpha-fetoprotein expression reached a peak and decreased dramatically after birth. Spearman correlation test showed that both proteins' expressions were correlated in the opposite direction $(\mathrm{P}<0.05$ and $\mathrm{r}=-0.695)$. In conclusion, Afamin and Alpha-fetoprotein have an opposite expression during development. The time point of intersection was ED18.5; implying the peak of hepatoblast proliferation to enter the differentiation process.
\end{abstract}

Keywords: Liver Development, Hepatoblast, Hepatocytes, Afamin, AlphaFetoprotein

\section{Introduction}

Liver is the largest mammals' visceral organ that occupies a central position in metabolism. Almost all nutrients absorbed by the gastrointestinal tract are transported to the liver through portal vein. Therefore, liver has a very important role to accommodate, alter and collect metabolites from the blood, as well as to neutralize and remove toxic substances in it. In addition, the hepatobiliary system allows liver to carry bile into the gastrointestinal tract (Spear et al., 2006; Mescher, 2013).

During prenatal development, Alpha-Fetoprotein (AFP) is produced at a high level by liver and yolk sac. AFP produced by the embryo can be transferred to the maternal blood circulation (Sell, 2008; Bredaki et al., 2011). After birth, AFP level falls rapidly and only a few 
can be detected in both serum and adult liver. Malignant Hepatocellular Carcinoma (HCC) is the most common malignancy and the third leading cause of cancer-related death (Sturgeon et al., 2010). Serum AFP levels increase in HCC (Soltani, 1979; Lazarevich, 2013) and rapidly return to normal after complete resection of HCC. Therefore, serial AFP serum levels may be used to monitor the treatment response of HCC patients (Adinolfi and Adinolfi, 1975; Lazarevich, 2013). In anencephaly and spina bifida are found to increase AFP levels, whereas in down syndrome AFP levels decrease (Salder, 2012; Lazarevich, 2013). Until now, none studies report a congenital liver disorder associated with AFP and Afamin (AFM). Nevertheless, there is an association between embryonic AFP and maternal blood circulation which allows the use of AFP for prenatal screening. Despite widespread clinical use of AFP, the role of AFP during the embryonic and fetal period is not entirely clear (Bélanger et al., 1994; Salder, 2012).

The high level of AFP expression during embryonic development indicates that AFP has an important role in the normal development of mammals. During pregnancy, it was thought that AFP plays an immunoregulatory role in suppressing the maternal immune system for pregnancy to be maintained (Murgita and Tomasi, 1975; Murgita, 1976). However, the results of (Gabant et al., 2002) showed that AFP is not essential for embryonic development, because mice with inactive AFP (AFP knockout/AFP null) can develop normally, although there is a fertility disorder in female mice.

Redundancy of genomic function in the genome is common in vertebrates (Salder, 2012). It is possible that the function of AFP during embryonic development overlaps with other proteins in Albumin family members that are closely related and have similar structural properties, i.e. albumin, afamin and vitamin D binding protein (Bélanger et al., 1994). AFM has an identical amino acid sequence with another albumin family member that is $33 \%$ identical to AFP, $29 \%$ identical to Albumin and $19 \%$ identical to vitamin D binding protein. AFM is produced by the liver, but its function is still very little known. Lichenstein et al. (1994) although there are indications that AFM may compensate for the absence of AFP during embryonic development, research on the dynamics of AFM expression and its correlation with AFP has not been reported. Therefore, an observational baseline study has been conducted to determine the pattern and distribution of AFP expression and its correlation with AFM expression in rat liver tissue during embryonic, neonatal and adult development.

\section{Methods}

Eighteen wistar embryos, neonates and adult rats were used as a research subject. The rats were grouped into six age groups (consisted of three rats in each group), i.e., four embryo groups (ED12.5, ED14.5, ED16.5 and ED18.5), neonates and adult (8-10 weeks). Animal handling (mating, harvesting the embryos, liver collections) was conducted in Animal House Laboratorium Badan Penelitian dan Pengembangan Kesehatan (Litbangkes) Republik Indonesia. Embryo handling was conducted at the Integrated Laboratory, Faculty of Medicine, Universitas Indonesia (FMUI). Paraffin embedding and Immunohistochemistry (IHC) staining were conducted at the Laboratory of Department of Pathological Anatomy FMUI. This research has received permission from Research Ethics Committee FMUI No. 466/UN2.F1/ETIK/VI/2016.

To meet the needs of research subjects, which consisted of six ages, six female rats were mated. Three embryos (ED12.5, ED14.5, ED16.5 and ED18.5), neonates, or adult rats were taken from each female. Female Wistar rats that have been mated at night were confirmed by the existence of copulation plug in the next morning. When the plug was found, the embryo's age was calculated as 0.5 days (ED 0.5) (Ochiogu et al., 2006; Sengupta, 2013; Swartley et al., 2016).

The rat livers were collected by performing a surgical process according to age. The ED12.5-16.5 embryos were released from the uterus under a binocular microscope, whereas ED18.5 embryos, neonatal and adult rats were sacrificed and the livers were taken macroscopically. All the embryos and the livers were fixed in a $10 \%$ buffer of formalin solution overnight at room temperature. After fixation, the embryos and livers were embedded and blocked in paraffin for further sectioning. During embedding and blocking, ED12.5 and ED14.5 embryos were positioned in the left lateral decubitus direction, whereas liver of ED16.5, ED18.5, neonates and adults were positioned in the Sagittal field.

Protein expression was detected using IHC staining against AFP (Abcam 1: 400, Ab 46799) and AFM (Cloud-Clone, 1:100, PAC284Ra01). The staining was considered positive if the cytoplasm of hepatoblasts/hepatocytes were brown colored. The staining results were analyzed using the IHC Profiler ImageJ program with an IHC optical density score. The correlation between AFM and AFP expression was statistically analyzed by the Spearman correlation test using SPSS 17 software.

\section{Results}

Our result showed that AFP was expressed during prenatal life and decreased after birth. AFP was expressed in hepatoblast and was distributed evenly in the liver tissue at ED12.5 until ED18.2. In neonate, the expression became weaker and expressed randomly with strong intensity around triad portal and central vein. The expression was lost in adult (Fig. 1). 

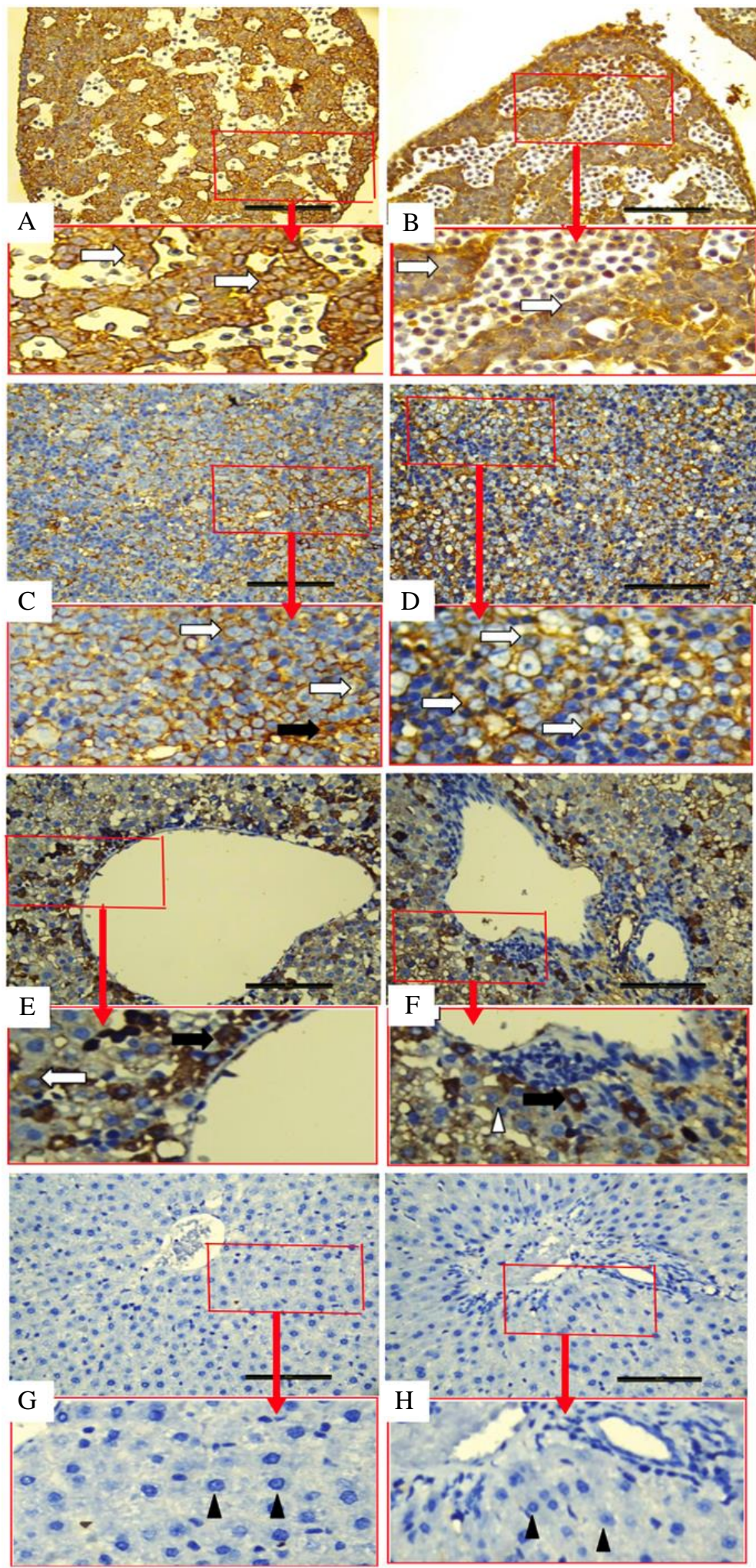

Fig. 1: AFP expression during rat liver development. (A) ED12.5. (B) ED14.5. (C) ED16.5. (D) ED18.5. (E) Neonates; paracentral. (F) Neonates; paraportal. (G) Adult; paracentral. (H) Adult; paraportal. Magnification of a picture in a red box is placed under it directly. Black arrowhead, negative cells; white arrowhead, weak expression; white arrow, fair expression; black arrow, strong expression; black bar, $50 \mu \mathrm{m}$ 


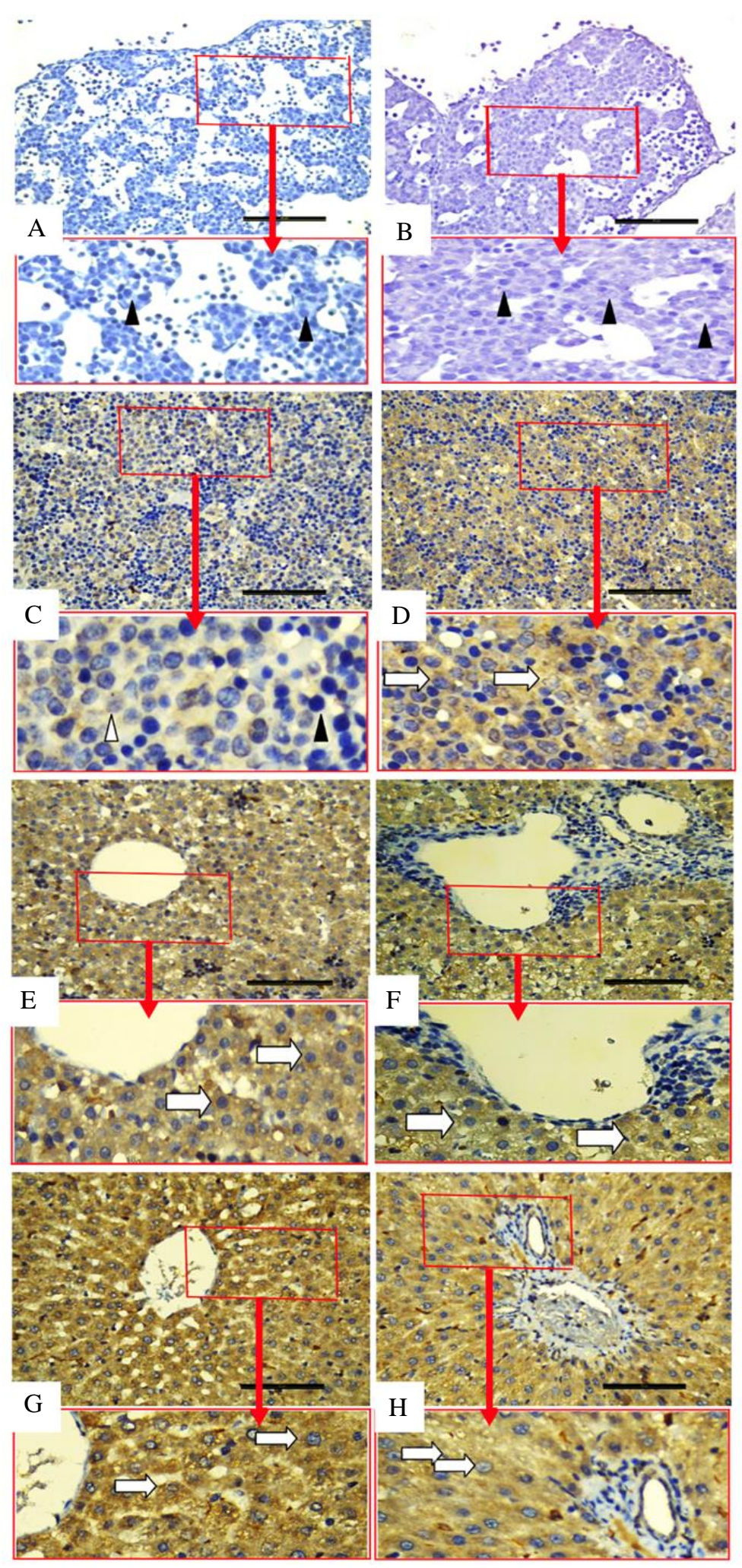

Fig. 2: AFM expression during rat liver development. (A) ED12.5. (B) ED14.5. (C) ED16.5. (D) ED18.5. (E) Neonates; paracentral. (F) Neonates; paraportal. (G) Adult; paracentral. (H) Adult; paraportal. Magnification of a picture in a red box is placed under it directly. Black arrowhead, negative cells; white arrowhead, weak expression; white arrow, fair expression; black arrow, strong expression; black bar, $50 \mu \mathrm{m}$ 


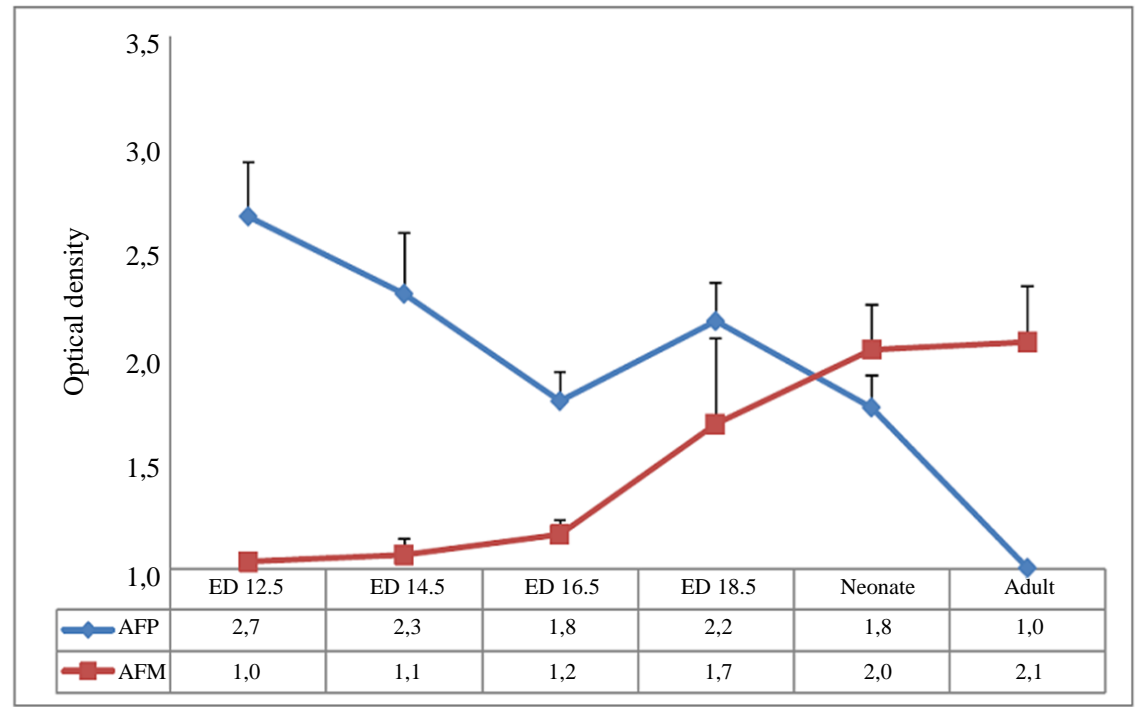

(A)

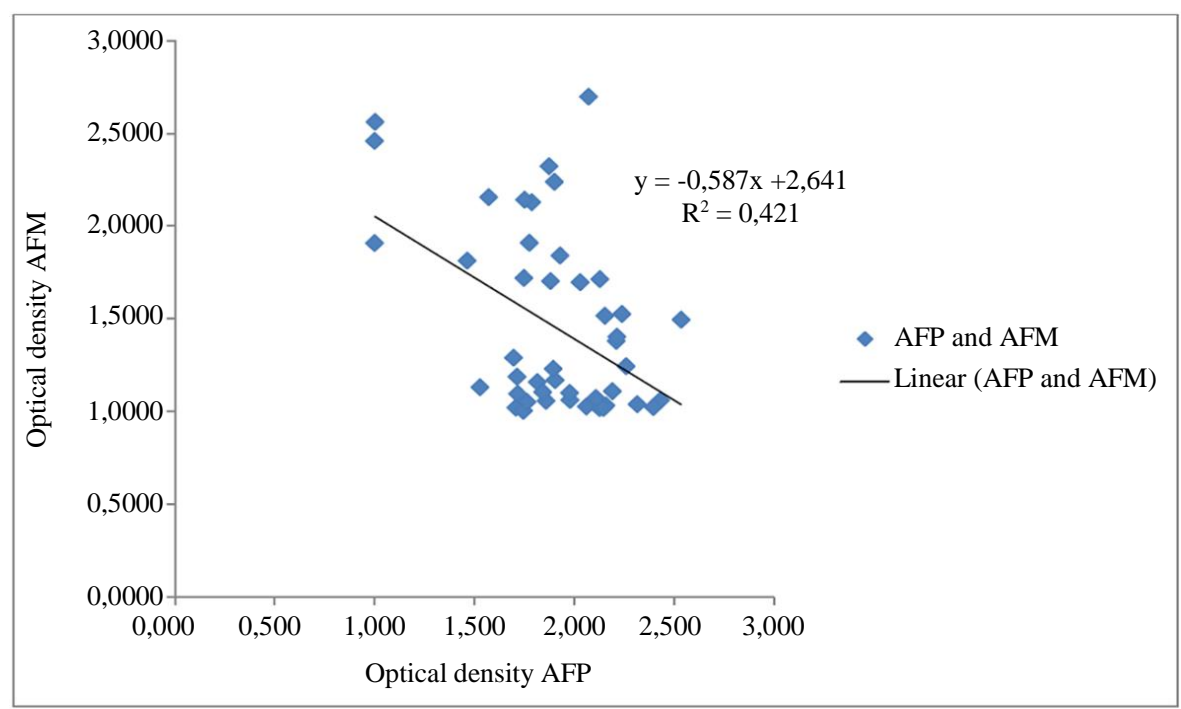

(B)

Fig. 3: AFP and AFM expression patterns during rat liver development. (A) AFP (blue line) has been exprressed in ED12.5. AFM (red line) starts to express in ED16.5. (B) Converse correlation of AFP and AFM

AFM began to be expressed prenatally and continued to be maintained in neonates and adults. It was expressed in the cytoplasm of hepatocytes, started from ED16.5 (weak expression). At ED18.5 to neonate it was distributed evenly on hepatocytes. In adult rat liver, the expression was retained on the hepatocytes either in the area around the central vein or the portal triad (Fig. 2).

The AFP expression pattern appeared to be opposite to AFM (Fig 3). AFP has been expressed at ED12.5 (strong expression), whereas the AFM has not been expressed in this time. The AFP reached it second peak of expression at ED18.5 and decreased after that, whereas with the progress of development the AFM expression increased and was retained after birth. The cross point of their expression was after ED18.5 before neonate. The Spearman correlation test showed a significant opposite direction of correlation between AFP and AFM $(\mathrm{p}<0.05$ and $\mathrm{r}=-0.695)$.

\section{Discussion}

The AFP had been expressed early during liver development compared to the AFM. AFP was expressed evenly since ED12.5, which is suggested to be related to hepatoblast proliferation (Elmaouhoub et al., 2007; Crawford et al., 2010). The AFM had not been expressed at this stage was presumably because 
hepatoblasts are still in the undifferentiated stage (Duncan, 2003). Research conducted by (Yachnin, 1978) in humans showed that AFP begins to express at 29 days of gestation. Based on this study, the onset of AFP expression in humans and rats was in accordance with the comparison timeline of the developmental stage between humans and rats (Hill, 2020).

AFP expression was maintained until ED18.5 then decreased steadily and disappeared in adults; whereas, AFM was continuing to be expressed and increased with ages and maintained after birth. The gradual decrease of AFP expression could happen because there was a gradual increase in hepatoblast differentiation. Hepatoblast differentiation in mice occurs in ED14.5 (based on Carnegie stage ED15.5-16) (Zorn, 2008; Crawford et al., 2010; Hill, 2020). Hepatoblasts are bipotential that can differentiate into hepatocytes and cholangiocytes. This hepatoblast differentiation will largely be hepatocytes (Zorn, 2008). These results were consistent with other studies (Nayak and Mital, 1977; Shiojiri et al., 1991; Elmaouhoub et al., 2007). Elmaouhoub et al. (2007) showed that after ED18.5 to birth, Proliferating Cell Nuclear Antigen (PCNA) decreased dramatically and so did the AFP.

This study result was in accordance with previous study. Shiojiri et al (1991) demonstrated that AFP expression increased during embryo's development, decreased before birth and ultimately did not express again in mature cells. Chou et al. (1988) stated that hepatocyte maturation can be monitored from decreased expression of AFP. Therefore, it can be attributed that hepatocytes are said to be mature if expressed AFM without AFP. Nevertheless, the underlying mechanism of the different times of AFP and AFM activation has to be revealed (Liu et al., 2011). Hepatoblast differentiation is thought to be influenced by HNF1 $\alpha$ and HNF1 $\beta$ activities (Coffinier et al., 2002; Liu et al., 2011). HNF1 $\beta$ deletion may cause defects of the biliary system and liver dysfunction (Coffinier et al., 2002).

Our result showed that AFM has a strong negative correlation with AFP. This study is in accordance with a study conducted by (Wu et al., 2000) who overexpressed the AFM on hepatocellular carcinoma cell lines resulting in proliferative inhibition of the cells. Therefore, the decrease of AFP expression could be caused by the increase of AFM expression, since AFM is expressed by differentiated cells. However, since the mechanism has not been known yet, further research is needed.

\section{Conclusion}

During liver development, AFP and AFM had a strong correlation in opposite directions. AFP expression started early, increased and reached a peak in ED18.5; after that, it continued to decrease and lost in adults. Whereas, AFM began to express in ED16.5-18.5 embryos. It expressed evenly, increased with age and was maintained after birth. Further study is needed to reveal the mechanism of this phenomenon.

\section{Acknowledgment}

We would like to thank the Department of Anatomy, Integrated Laboratory and Pathological Anatomy, Faculty of Medicine, Universitas Indonesia, for the project development and for providing us with support in this study.

\section{Funding Information}

The research was supported by Hibah Publikasi Internasional Terindeks untuk Tugas Akhir (PITA) Mahasiswa UI 2018.

\section{Author's Contributions}

All authors equal contribution to this paper.

\section{Ethics}

This Research has received permission from the Research Ethics Committee of Faculty of Medicine, Universitas Indonesia No. 466/UN2.F1/ETIK/VI/2016.

\section{References}

Adinolfi, A. N. N. A., \& Adinolfi, M. (1975). Alphafeto-protein during development and in disease. Journal of Medical Genetics, 12(2), 138-151.

Bélanger, L., Roy, S., \& Allard, D. (1994). New albumin gene 3 'adjacent to the alpha 1-fetoprotein locus. Journal of Biological Chemistry, 269(8), 5481-5484.

Bredaki, F. E., Wright, D., Akolekar, R., Cruz, G., \& Nicolaides, K. H. (2011). Maternal serum alphafetoprotein in normal pregnancy at 11-13 weeks' gestation. Fetal diagnosis and therapy, 30(4), 274-279.

Chou, J. Y., Wan, Y. J., \& Sakiyama, T. A. K. E. S. H. I. (1988). Regulation of rat liver maturation in vitro by glucocorticoids. Molecular and cellular biology, 8(1), 203-209.

Coffinier, C., Gresh, L., Fiette, L., Tronche, F., Schütz, G., Babinet, C., ... \& Barra, J. (2002). Bile system morphogenesis defects and liver dysfunction upon targeted deletion of HNF1 $\beta$. Development, 129(8), 1829-1838.

Crawford, L. W., Foley, J. F., \& Elmore, S. A. (2010). Histology atlas of the developing mouse hepatobiliary system with emphasis on embryonic days 9.5-18.5. Toxicologic pathology, 38(6), 872-906.

Duncan, S. A. (2003). Mechanisms controlling early development of the liver. Mechanisms of development, 120(1), 19-33. 
Elmaouhoub, A., Dudas, J., \& Ramadori, G. (2007). Kinetics of albumin-and alpha-fetoproteinproduction during rat liver development. Histochemistry and cell biology, 128(5), 431-443.

Gabant, P., Forrester, L., Nichols, J., Van Reeth, T., De Mees, C., Pajack, B., ... \& Szpirer, J. (2002). Alphafetoprotein, the major fetal serum protein, is not essential for embryonic development but is required for female fertility. Proceedings of the National Academy of Sciences, 99(20), 12865-12870.

Hill, M. A. (2020). Rat development, UNSW. Embryology. ISBN: 9780733426094 - UNSW CRICOS Provider Code No. 00098G

Lazarevich, N. L. (2013). AFP (alpha-fetoprotein). Atlas of Genetics and Cytogenetics in Oncology and Haematology.

Lichenstein, H. S., Lyons, D. E., Wurfel, M. M., Johnson, D. A., McGinley, M. D., Leidli, J. C., ... \& Zukowski, M. M. (1994). Afamin is a new member of the albumin, alpha-fetoprotein and vitamin Dbinding protein gene family. Journal of Biological Chemistry, 269(27), 18149-18154.

Liu, H., Ren, H., \& Spear, B. T. (2011). The mouse alpha-albumin (afamin) promoter is differentially regulated by hepatocyte nuclear factor $1 \alpha$ and hepatocyte nuclear factor $1 \beta$. DNA and cell biology, 30(3), 137-147.

Mescher, A. L. (2013). Junqueira's basic histology: text and atlas (Vol. 12). 13th ed. New York: McGrawHill Medical.

Murgita, R. A. (1976). The immunosuppressive role of alpha-fetoprotein during pregnancy. Scandinavian journal of immunology, 5(9), 1003-1014.

Murgita, R. A., \& Tomasi Jr, T. B. (1975). Suppression of the immune response by alpha-fetoprotein on the primary and secondary antibody response. The Journal of experimental medicine, 141(2), 269-286.

Nayak, N. C., \& Mital, I. (1977). The dynamics of alphafetoprotein and albumin synthesis in human and rat liver during normal ontogeny. The American journal of pathology, 86(2), 359.

Ochiogu, I. S., Uchendu, C. N., \& Ihedioha, J. I. (2006). A new and simple method of confirmatory detection of mating in albino rats (Rattus norvegicus). Animal Research International, 3(3), 527-530.
Salder, T. W. (2012). Langman Embriologi Kedokteran. 10th Edn. Edited by A. Novrianti. EGC, Jakarta. ISBN: 978-979-044-010-4

Sell, S. (2008). Alpha-fetoprotein, stem cells and cancer: how study of the production of alpha-fetoprotein during chemical hepatocarcinogenesis led to reaffirmation of the stem cell theory of cancer. Tumor Biology, 29(3), 161-180.

Sengupta, P. (2013). The laboratory rat: relating its age with human's. International journal of preventive medicine, 4(6), 624.

Shiojiri, N., Lemire, J. M., \& Fausto, N. (1991). Cell lineages and oval cell progenitors in rat liver development. Cancer Research, 51(10), 2611-2620.

Soltani K. (1979). Alpha-Fetoprotein: A Review. The Journal of Investigative Dermatology, 72(5):211-213.

Spear, B. T., Jin, L., Ramasamy, S., \& Dobierzewska, A. (2006). Transcriptional control in the mammalian liver: liver development, perinatal repression and zonal gene regulation. Cellular and Molecular Life Sciences CMLS, 63(24), 2922-2938.

Sturgeon, C. M., Duffy, M. J., Hofmann, B. R., Lamerz, R., Fritsche, H. A., Gaarenstroom, K., ... \& Diamandis, E. P. (2010). National Academy of Clinical Biochemistry Laboratory Medicine Practice Guidelines for use of tumor markers in liver, bladder, cervical and gastric cancers. Clinical chemistry, 56(6), e1-e48.

Swartley, O. M., Foley, J. F., Livingston III, D. P., Cullen, J. M., \& Elmore, S. A. (2016). Histology Atlas of the Developing Mouse Hepatobiliary Hemolymphatic Vascular System with Emphasis on Embryonic Days 11.5-18.5 and Early Postnatal Development. Toxicologic pathology, 44(5), 705-725.

Wu, G. X., Lin, Y. M., Zhou, T. H., Gao, H., \& Pei, G. (2000). Significant down-regulation of alphaalbumin in human hepatoma and its implication. Cancer Letters, 160(2), 229-236.

Yachnin, S. T. A. N. L. E. Y. (1978). The clinical significance of human alpha-fetoprotein. Annals of Clinical \& Laboratory Science, 8(2), 84-90.

Zorn, A. M. (2008). Liver development. StemBook. The Stem Cell Research Community. 